\title{
Comunicar compreende o quê?
}

DOI: 10.1590/1809-58442017117

\section{Marcilene do Carmo de Oliveira Miranda}

(Universidade Federal do Pará, Instituto de Letras e Comunicação, Programa de Pós-Graduação Comunicação, Cultura e Amazônia. Belém - PA, Brasil)

\section{Suzana Cunha Lopes}

(Universidade Federal de Minas Gerais, Faculdade de Filosofia e Ciências Humanas, Programa de Pós-Graduação em Comunicação Social. Belo Horizonte - MG, Brasil)

FRANÇA, Vera V.; SIMÕES, Paula G. Curso Básico de Teorias da Comunicação. Belo Horizonte: Autêntica Editora, 2016. 219p.

O Curso Básico de Teorias da Comunicação é uma obra que se soma e qualifica o sempre complexo universo das Teorias da Comunicação, com uma proposta reflexiva sobre a trajetória da área e com um diferencial em relação a outros livros: uma orientação teórica explícita e propositiva, em tom didático, para auxiliar tanto professores como alunos.

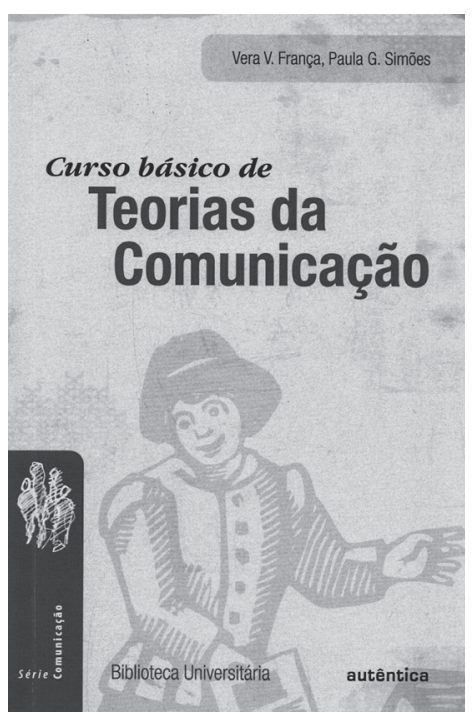

As autoras iniciam e finalizam o livro contando a história de sua elaboração, compartilhando com o leitor os desafios de lidar diariamente em sala de aula com a formação de comunicadores e dimensionando a importância das teorias para orientar, atualizar e tensionar a pesquisa e a prática comunicacionais. Como professoras, e outrora alunas, França e Simões contextualizam as contingências que envolvem a produção de conhecimento, conferindo ao livro uma importância ainda maior, além do seu próprio conteúdo. Mostram o quanto o conhecimento é fruto de trajetórias, enfrentamentos, aprimoramentos, retornos e avanços e, sobretudo, é um trabalho coletivo.

O caráter didático se configura também por uma abordagem reflexiva das autoras em todo o texto: elas pontuam os marcos teóricos articulados à constituição da área da Comunicação, evidenciando a importância desses conteúdos para a compreensão da área na atualidade, independentemente da posição teórica que defendem. Os primeiros estudos empíricos e as pesquisas científicas realizadas constituem a base para a compreensão, por exemplo, da extensão curricular da área, bem como das discussões em torno do objeto de estudo da Comunicação. 
Do ponto de vista do conteúdo, a obra apresenta uma organização das escolas, teorias e autores conforme sua localização geográfica e orientação epistemológica, focalizando nos estudos norte-americanos, europeus e latino-americanos, apesar de, como explicam as autoras, algumas teorias e pensadores não se enquadrarem em categorias, rendendo tópicos à parte. Nesse sentido, é interessante o reconhecimento do quanto a dinâmica das Teorias da Comunicação, mesmo passível de sistematização, precisa ser pensada de maneira menos linear, percebendo-se os desdobramentos históricos de como a Comunicação foi vista, revista e ainda o é.

Seja tratando da Mass Communication Research, da Escola de Chicago, da Teoria Crítica, dos Estudos Culturais Ingleses ou da Escola Latino-americana, os capítulos apresentam didaticamente os contextos sócio históricos e a orientação filosóficoepistemológica em que as teorias foram desenvolvidas, além dos detalhes institucionais e interpessoais ora envoltos, dos pesquisadores e teóricos que as propuseram e do conteúdo em si das teorias, explicitando suas especificidades em meio ao conjunto de uma escola de pensamento.

Mesmo respeitando as diferentes contribuições das escolas de pensamento, as autoras também se posicionam teoricamente, tendo a Escola de Chicago e o Interacionismo Simbólico como principal referência. Não à toa o destaque dado aos autores e às propostas dessa escola em um capítulo próprio, evidenciando sua pertinência para pensar a comunicação hoje, apesar de serem cronologicamente contemporâneos e até anteriores à Mass Communication Research nos Estados Unidos, o que por vezes é pouco lembrado ou mesmo ausente em outras obras de Teorias da Comunicação.

Outro destaque da obra é o capítulo inicial sobre a comunicação como fenômeno e como área de conhecimento. Partindo da indagação “O que é, afinal, comunicação?”, as autoras discorrem desde as situações mais comuns de interação até os aspectos que conferem status científico a uma problemática social, que se institucionaliza. Ao discutirem o que é teoria e o que é ciência, buscam problematizar a permanente dualidade da comunicação em ser ao mesmo tempo objeto empírico e objeto de estudo, o que é a principal riqueza e desafio da área em sua constituição epistemológica.

Assim como se posicionam em relação às teorias, do ponto de vista epistemológico, as autoras defendem que o objeto de estudo da Comunicação é a própria comunicação, em sua diversidade teórica e prática na sociedade. Os processos comunicativos, portanto, seriam o viés a partir do qual os estudos na área olham as dinâmicas sociais, problematizam-nas e buscam sua compreensão e transformação. Por isso, acreditam que a comunicação é da ordem do fazer, do saber fazer, mas também do saber sobre o fazer, por isso o diálogo entre teoria e empiria/prática são imprescindíveis para o exercício de construção de conhecimento na área. 
Discutem, por fim, o paradigma informacional que orientou e continua orientando várias teorias e escolas, ainda que com posições e desdobramentos distintos. Reconhecendo as limitações desse paradigma que vê o processo comunicativo como linear, propõem outra perspectiva para pensar o comunicacional: a abordagem relacional, que toma a comunicação como um processo complexo, tecido por diferentes fatores, agentes e contingências.

Contudo, após partirem de um lugar teórico e proporem conceituações e abordagens, ao finalizarem o livro, França e Simões buscam caracterizar o cenário contemporâneo, marcado não somente pelo crescimento e fortalecimento institucional da área, mas também por uma profusão de estudos com vieses bastante diferenciados e que revelam uma abrangência teórica muito difícil de ser diagnosticada e analisada.

Hoje é possível ter maior clareza, mesmo que não haja consenso entre os pesquisadores, de quais Escolas e autores se tornaram grandes referenciais para a área. O mapa das Teorias da Comunicação do século XXI, contudo, está em aberto e em construção para novos empreendimentos de sistematização. Em que medida as tradições teóricas dos Estudos Culturais e de autores como Marshall McLuhan, entre outros, orientam nossas pesquisas até hoje e quais outras e novas referências a área tem despontado? Ao traçar o panorama dos estudos comunicacionais, as autoras nos oferecem subsídios para pensar como a Comunicação se tornou um saber científico e institucionalizado, além do quanto ainda temos o desafio de analisar o comunicacional nos diferentes fenômenos sociais, compreendendo qual é, de fato, a contribuição da nossa área para entender o contemporâneo.

\section{Marcilene do Carmo de Oliveira Miranda}

Graduada em Letras (2002), com especialização em Língua Portuguesa: uma abordagem textual (2004) e em Gestão Escolar (2010), todas as formações pela Universidade Federal do Pará (UFPA). Mestre em Ciências da Comunicação (2016) pelo Programa de Pós-Graduação Comunicação, Cultura e Amazônia da UFPA. Integrante do Grupo de Pesquisa em Processos de Comunicação (Pespcom), certificado pelo CNPq. Atualmente é docente do ensino básico no município de Cametá, atuando na rede estadual de ensino público do Estado do Pará (Colégio Estadual de Ensino Médio Júlia Passarinho) e na rede municipal (Escola Municipal de Ensino Fundamental Raimunda da Silva Barros). E-mail: marcilene.omiranda@gmail.com.

\section{Suzana Cunha Lopes}

Doutoranda em Comunicação Social no Programa de Pós-Graduação em Comunicação Social da Universidade Federal de Minas Gerais (UFMG). Mestre em Ciências da Comunicação (2013) pelo Programa de Pós-Graduação Comunicação, Cultura e Amazônia da Universidade Federal do Pará (UFPA). Graduada em Comunicação Social - habilitação em Jornalismo (2010) pela UFPA. É integrante do Grupo de Pesquisa em Processos de Comunicação (Pespcom) e do Grupo de Pesquisa em Imagem e Sociabilidade (Gris), ambos certificados pelo CNPq. E-mail: suzanaclopes@yahoo.com.br.

Recebido em: 13.04.2017

Aceito em: 20.04.2017 